\title{
Sucrose Transport into Citrus Juice Cells: Evidence for an Endocytic Transport System
}

\author{
Ed Etxeberria and Pedro Gonzalez \\ University of Florida, IFAS, Citrus Research and Education Center, 700 Experiment Station Road, \\ Lake Alfred, FL 33850 \\ Javier Pozueta-Romero \\ Agrobioteknologia eta Natura Baliabideetako Instituta, Nafarroako Unibertsitate Publikoa eta CSIC, \\ Mutilako etorbidea zenbaki gabe, 31192 Mutiloabeti, Nafarroa, Spain
}

\begin{abstract}
AdDitional INDEX WORDS. Citrus reticulata, apoplast, post-phloem transport, sucrose transport, symplast, vacuole
Aвstract. To investigate the mechanisms of sucrose transport and its accumulation into 'Murcott' mandarin (Citrus reticulata Blanco) fruit, developmental changes in determinants of sink strength such as sucrose metabolizing enzymes, and sucrose transport across both plasmalemma and tonoplast were analyzed. Concurrently with sucrose levels, sucrose synthase, sucrose phosphate synthase and sucrose phosphate phosphatase increased throughout fruit development. Plasmalemma and tonoplast vesicles isolated from fruit collected at different developmental stages were analyzed for their transport capabilities. Sucrose uptake into energized plasmalemma vesicles was abolished by gramicidin, which is in accordance with the presence of an active symport mechanism of sucrose transport from the apoplast into the cytosol. Unexpectedly, tonoplast vesicles were shown to lack active transport mechanism of sucrose into the vacuole. More importantly, however, and in conformity with recent findings showing the occurrence of an endocytic mechanism of ion uptake in maize (Zea mays L.) root cells, citrus (Citrus L.) juice cells were shown to incorporate membrane impermeable dyes into their vacuoles in the presence of sucrose. High definition confocal microscopy revealed the co-localization of membrane impermeable markers in cytoplasmic vesicles and the formation of vesicles at the plasmalemma. The data provide evidence for an endocytic system of transport that allows direct incorporation of sucrose from the apoplast to the vacuole bypassing both the plasmalemma and tonoplast.
\end{abstract}

Post-phloem transport of sucrose into terminal sink organs is a dynamic process that can take one of two routes depending on the type of organ and developmental state (Patrick, 1997). Sucrose can be transported through the symplastic continuum when adequate plasmodesmata connections exist between storage cells (symplastic route). Alternatively, sucrose transport can take place through the apoplasm after its release from the phloem terminus (apoplastic route). In some cases, however, both types of post-phloem transport systems may operate simultaneously, or may function sequentially at different stages during ontogeny. The symplastic route seems to be the predominant pathway in most tissues investigated, whereas the apoplasmic step is largely associated with sinks containing different genomes (such as seeds) and those which accumulate high concentrations of soluble sugars (Patrick, 1997).

Citrus fruits accumulate sucrose in their juice cells at concentrations up to $250 \mathrm{~mm}$ (Soule and Grierson, 1986). Accumulation of sucrose begins in late summer (Soule and Grierson, 1986) with rates accelerating during the autumn months as the fruit attains its final size. Existing evidence indicates that post-phloem transport of sucrose into the juice vesicles (sac-like structures containing juice cells) occurs via the apoplastic route (Koch and Avigne, 1990) and with very little inversion (Koch, 1984; Koch and Avigne, 1990). Whether the rates of sucrose accumulation and storage into juice cells are restricted by the presence of membrane-bound carriers or dominated by other physiological constraints is not known, given that transport across juice cell membranes has not been investigated.

Received for publication 4 Aug. 2004. Accepted for publication 13 Sept. 2004. This work was supported in part by a grant from the Rural Development Administration of Korea and by the Florida Agricultural Experiment Station, and approved for publication as Journal Series No.R-10251.
Apoplastic transport into terminal sink cells carries the inherent premise that solutes to be accumulated in the vacuole have to be transported across two sets of membranes (i.e., plasmalemma and tonoplast). Despite the critical relevance of these processes to the overall understanding of sink strength and plant productivity, very little is known about the combined transport of sugars across both the pasmalemma and tonoplast of sink cells. Whereas the tonoplast sucrose $/ \mathrm{H}^{+}$antiport has been demonstrated in a few cell types such as table beet (Beta vulgaris L.) hypocotyl (Getz, 1991) and japanese artichoke (Stachys sieboldii Miq.) tubers (Keller, 1992), the plasmalemma sucrose $/ \mathrm{H}^{+}$symport is well documented mostly as part of the phloem loading process, and only indirectly inferred for storage tissues (Manning et al., 2001; Rosche et al., 2002).

To further our knowledge into the process of sugar accumulation in citrus fruit (and hence fruit quality) and plant productivity in general, we investigated several aspects associated with sink strength including enzymes of sucrose metabolism, membrane-associated proton pumping capacity, and most importantly, sucrose transport across both the plasmalemma and tonoplast throughout fruit development. Results presented in this work strongly indicate that sucrose import from the apoplast to the cytosol of citrus juice cells takes place by means of a carrier-mediated electrogenic transport mechanism. In addition, the data suggest the presence of an endocytic system for the transport of sucrose from the apoplast to the vacuole.

\section{Materials and Methods}

Plant Material. 'Murcot' mandarins were collected monthly between 6 Aug. 2002 and the end of Jan. 2003 from groves located at the Citrus Research and Education Center in Lake Alfred, Fla. 
A total of 10 fruit were used per sample. Collected fruit were taken immediately from the field to the laboratory and used for fruit analyses, enzyme extraction, and membrane isolation. Five fruit were used for membrane isolation, and the remaining five for extraction of soluble enzymes. The experiments were run in triplicates for each sampling point from a total of 30 fruit.

ENZYME EXTRACTION. Each fruit was weighed and cross-sectioned at the equator. From each half of five fruit, $1 \mathrm{~mL}$ juice was mixed with $1 \mathrm{~mL}$ of cold buffer containing $0.5 \mathrm{M} 3-(N$-morpholino) propanesulfonic acid (MOPS)-KOH (pH 8.0), $14 \mathrm{~mm}$ mercaptoethanol, 4 mm ethylene glycol-bis(ß-aminoethyl ether)- $N$, $N, N^{\prime}, N^{\prime}$-tetraacetic adid (EGTA), $1.5 \%$ polyvinyl-pyrrolidone (PVP-40) and $1 \mathrm{~mm}$ phenylmethylsulfonyl fluoride (PMSF). All aliquots were combined and the buffered juice centrifuged at 77,000 $g_{n}$ for $30 \mathrm{~min}$ at $4^{\circ} \mathrm{C}$. After centrifugation, $2.5 \mathrm{~mL}$ of the supernatant was desalted through a Sephadex PD-10 column pre-equilibrated with a buffer containing $10 \mathrm{~mm}$ 4(-2-hydroxyethyl)-1-piperazeneethanesulfonic acid (HEPES, pH 7.0), 2 mM dithiothreitol (DTT), and $1 \mathrm{~mm} \mathrm{MgCl}_{2}$. Three milliliters were collected for enzyme assays.

Juice $\mathrm{pH}$ and titratable acids were measured individually for each of the five unbuffered fruit-juice extracts. Juice $\mathrm{pH}$ (15 $\mathrm{mL}$ ) was measured using a $\mathrm{pH}$ meter (model HI-9219; Hannah Instruments, Woonsocket, R.I.) and titrated to an end point $\mathrm{pH}$ of 8.0 using standard alkali solution $(0.3125 \mathrm{~N} \mathrm{NaOH})$. For sucrose analysis, samples of juice were clarified by centrifugation at $20,000 g_{\mathrm{n}}$ and sucrose concentration determined by the anthrone method of Van Handel (1968).

Plasmalemma AND tonoplast isolation. Plasmalemma and tonoplast were isolated following the procedure described by Etxeberria and Gonzalez (2003), a method that combines the principles of sucrose density gradient and aqueous two-phase partition. Approximately $150 \mathrm{~mL}$ of juice cell extract was squeezed directly into $150 \mathrm{~mL}$ of homogenization buffer containing 0.5 м MOPS/KOH (pH 8.0), $0.5 \%$ PVP-40, 4 mм DTT, 3.5 mм ethylenediamine-tetraacetic acid (EDTA), $250 \mathrm{~mm}$ sucrose, 0.1 $\mathrm{mg} \cdot \mathrm{mL}^{-1} \mathrm{BSA}$, and $1 \mathrm{~mm}$ PMSF. After squeezing through two layers of cheesecloth, the homogenate was centrifuged at 10,000 $g_{\mathrm{n}}$ for $10 \mathrm{~min}$ to eliminate debris. The supernatant was centrifuged for $30 \mathrm{~min}$ at $40,000 \mathrm{~g}_{\mathrm{n}}$, and the pellet set aside for plasmalemma purification by aqueous two-phase partitioning. The remaining supernatant was centrifuged at 100,000 $g_{n}$ for an additional 60 min, and the pellet used for tonoplast purification by sucrose density gradient (Etxeberria and Gonzalez, 2003).

ENZYME ASSAYs. Sucrose synthase (SuSy) was assayed in the synthesis direction in a solution containing $100 \mathrm{~mm}$ HEPES ( $\mathrm{pH}$ 7.2), 2 mм uridine 5'-diphosphoglucose(UDPG), 10 mm fructose, $2 \mathrm{mM} \mathrm{MgCl}_{2}$, and $100 \mu \mathrm{L}$ protein extract in a final volume of $500 \mu \mathrm{L}$. Aliquots of $100 \mu \mathrm{L}$ were taken at 0, 20, 40, and $60 \mathrm{~min}$, mixed with $100 \mu \mathrm{L}$ of $30 \% \mathrm{KOH}$ and boiled for $10 \mathrm{~min}$. Sucrose remaining was determined following the anthrone method of van Handel (1968).

For sucrose phosphate synthase (SPS) the reaction mixture contained $100 \mathrm{~mm}$ HEPES (pH 7.5), 7.5 mM UDPG, 7.5 mM fructose-6-phosphate (F-6-P), $37.5 \mathrm{~mm}$ glucose-6-phosphate (G-6-P), $18 \mathrm{~mm} \mathrm{MgCl}_{2}, 1.0 \mathrm{mM}$ EDTA, and $100 \mu \mathrm{L}$ enzyme extract in a final volume of $500 \mu \mathrm{L}$. The reaction was terminated and analyzed for sucrose and sucrose-6-P (S-6-P) as for sucrose synthase.

Sucrose phosphate phosphatase (SPP) activity was assayed in a solution containing $100 \mathrm{~mm}$ 2-morpholonoethanesulfonic acid (MES) (pH 6.5), 10 mM $\mathrm{MgCl}_{2}, 2$ mM S-6-P, and $100 \mu \mathrm{L}$ enzyme extract in a total volume of $500 \mu \mathrm{L}$. Aliquots of $50 \mu \mathrm{L}$ were taken at specific times and mixed with $250 \mu \mathrm{L}$ of $7.2 \%$ SDS to stop the reaction. Released $\mathrm{P} i$ was determined at $850 \mathrm{~nm}$ by the method of Chifflett et al. (1988).

Total ATPase activity was determined using $25 \mu \mathrm{g}$ tonoplast or plasmalemma vesicle protein, $50 \mathrm{~mm}(1,3-$ bis[tris(hydroxymethyl)-methylamino]propane) (BTP)/MES ( $\mathrm{pH} 7.5), 250 \mathrm{~mm}$ sorbitol, $50 \mathrm{~mm} \mathrm{KCl,} \mathrm{BSA} \mathrm{at} 0.4 \mathrm{mg} \cdot \mathrm{mL}^{-1}$, $2 \mathrm{~mm}$ DTT, $10 \mu \mathrm{M}$ gramicidin, $3 \mathrm{~mm}$ ATP, and $3 \mathrm{~mm} \mathrm{MgSO}_{4}$ adjusted to a total volume of $500 \mu \mathrm{L}$. Aliquots of $50 \mu \mathrm{L}$ were removed from the assay at determined times and the product $\mathrm{P} i$ determined as for SPP.

Sucrose UPTAKe EXPERIMENTs. Assay mixtures for sucrose uptake into either tonoplast or plasmalemma vesicles contained the following: $50 \mu \mathrm{g}$ tonoplast or plasmalemma vesicle protein, $50 \mathrm{~mm} \mathrm{BTP/MES} \mathrm{at} \mathrm{pH} 7.5$ or $5.5,250 \mathrm{~mm}$ sorbitol, BSA at $0.4 \mathrm{mg} \cdot \mathrm{mL}^{-1}, 2 \mathrm{~mm}$ DTT, and $3 \mathrm{~mm}{ }^{14} \mathrm{C}$-sucrose $\left(5.18 \times 10^{4}\right.$ $\mathrm{Bq} \cdot \mu \mathrm{mol}^{-1}$ ) as described by Echeverria et al. (1997). $\mathrm{pH}$ jump energization for tonoplast experiments consisted in incubating tonoplast vesicles with lumellar $\mathrm{pH}$ of 5.5 in uptake medium at pH 7.5. Plasmalemma samples, which had been equilibrated at $\mathrm{pH} 7.5$, were incubated in a medium at $\mathrm{pH}$ 5.5.

Control experiments contained $10 \mu \mathrm{M}$ gramicidin (to dissipate the electrochemical potential gradient). Assays were run for 30 min with $100-\mu$ L aliquots taken at $0,10,20$, and $30 \mathrm{~min}$. Aliquots were removed at the indicated times and membranes washed on pre-rinsed cellulose nitrate filters (pore size $0.22 \mu \mathrm{m}, 25 \mathrm{~mm}$ in diameter; Whatman Intl., Maidstone, U.K.). After vacuum (625 $\mathrm{mm} \mathrm{Hg}$ ) was applied, the vesicles were washed with $5 \mathrm{~mL}$ storage buffer (Echeverria et al., 1997). Radioactivity retained in the vesicles was determined by scintillation spectroscopy after placing the filter disks in 5 mL of ScintiVerse BD SX 18-4 (Fisher Scientific, Pittsburgh). Control vesicle samples with gramicidin accumulated sucrose levels which corresponded to the predicted values calculated using vesicle void volume (Echeverria et al., 1997).

TiSSUE INCUBATION IN FLUORESCENT PROBES. Juice sacs (containing juice cells) from fruit at rapid stage of sucrose accumulation, were excised carefully and cut in halves. Ten halves were incubated in $3 \mathrm{~mL}$ of a solution containing $50 \mathrm{~mm} \mathrm{MES} \mathrm{buffer} \mathrm{(} \mathrm{pH} 5.5$ ), 250 mu sucrose, $0.1 \mathrm{~mm} \mathrm{CaCl}, 1 \mathrm{~mm} \mathrm{MgCl}_{2}$ and $1 \mathrm{mg} \cdot \mathrm{mL}^{-1} \mathrm{~d}-\mathrm{TR}$ (dextran MW 3,000 tagged with Texas Red; Molecular Probes, Eugene, Ore.) or $100 \mu \mathrm{M}$ Alexa 488 (Molecular Probes, Eugene, Ore). After approximately $24 \mathrm{~h}$ incubation in the dark at room temperature, the solution was drawn and substituted by $5 \mathrm{~mL}$ of $100 \mathrm{~mm}$ MES buffer (pH 5.5), 400 mm mannitol, $0.1 \mathrm{~mm} \mathrm{CaCl}_{2}, 1$ $\mathrm{mm} \mathrm{MgCl}_{2}, 1 \%$ Cellulase (Onozuka R-10; Yakult Pharmaceuticals Ind. Co., Tokyo) and 0.5\% Pectolyase Y-23 (Seishin Enterprise Co., Tokyo). After $2 \mathrm{~h}$, the released protoplasts were viewed under a microscope equipped with appropriate filters.

\section{Results and Discussion}

Transport of photoassimilates into storage cells constitutes an important step in the overall determination of sink strength and plant productivity, and may involve one or more transport mechanisms. In citrus fruit, post-phloem movement of photoassimilates into juice cells occurs through the apoplasm (Koch and Avigne, 1990), suggesting that key controlling steps leading to sugar accumulation reside at the plasmalemma and/or tonoplast. In an effort to determine the mechanisms of sucrose uptake and accumulation in storage juice cells, we investigated changes in specific factors known to be determinants of sink strength and their 
relationship to increases in sucrose content throughout development in 'Murcott' mandarin.

As in other citrus fruit, sucrose accumulation in 'Murcott' mandarin commenced at a time of rapid fruit expansion (Fig. 1A) and increasing juice $\mathrm{pH}$ [which directly reflects vacuolar $\mathrm{H}^{+}$ concentration (Echeverria and Burns, 1989; Echeverria et al., 1992)] (Fig. 1B). During the experimental period starting in early Aug. 2002, sucrose content increased from $\approx 115$ to 170 $\mathrm{mm}$ at the end of Jan. 2003. Concurrently, fruit diameter expanded from 55 to $82 \mathrm{~cm}$ (Fig. 1A). Acidity declined $\approx 60 \%$ with a concomitant raise in $\mathrm{pH}$ from 2.7 to 3.5 during the same period (Fig. 1B). Although organic acids are known to be utilized as an energy source and as intermediates for the synthesis of other organic compounds at later stages of development(Murata, 1977), most of the noted decline in acidity and corresponding increase in $\mathrm{pH}$ reported here were likely the result of utilization (Murata, 1977) and dilution, given the concurrent increase in vacuolar V-ATPase $\mathrm{H}^{+}$pumping activity (Fig. 2). Whereas tonoplastbound V-ATPase more than doubled, plasmalema P-ATPase increased over $50 \%$ during the same period. The increase in the cell's potential capacity to acidify both the apoplast and vacuole by their respective $\mathrm{H}^{+}$pumps is in conformity with the existence of $\mathrm{H}^{+}$-energized carriers at both membranes.

Enzymes of sucrose metabolism identified as indicators of sink strength in citrus fruit (Hockema and Etxeberria, 2001) and other tissues (Black et al., 1995), followed a pattern expected of a growing sink organ (Fig. 3). During our experiments, we noted significant changes in both soluble and tonoplast-associated protein as fruit matured, therefore, enzyme activities are expressed in a fruit basis to reflect changes against a specific unit of tissue. SuSy activity was highest throughout, and increased 6-fold during the experimental period (Fig. 3). Although SuSy intracellular location was not identified in the experiments presented here, its activity in rapidly growing tissues has been linked to the rapid utilization of sucrose for wall synthesis (Amor et al., 1995) and energy production (Hockema and Etxeberria, 2001). The delayed increase in SPS and SPP activities compared to SuSy (Fig. 3) suggests an increase in sucrose re-synthesis in the cytosol during the last stages of fruit development. Given that most sugars in citrus fruit arrive at the juice cells in the form of sucrose, increasing SPS and SPP activities are likely associated with re-synthesis of sucrose from some of the fructose moieties released by SuSy.

To gain further understanding on the sucrose accumulation process, the mechanisms of sucrose transport into juice cells was examined using tightly sealed plasmalemma and tonoplast vesicles isolated by a procedure developed for citrus juice cells (Etxeberria and Gonzalez, 2003). When plasmalemma vesicles were incubated in the presence of sucrose and of an imposed $\Delta \mu \mathrm{H}^{+}$, sucrose uptake was significantly higher than in control samples containing $10 \mu \mathrm{M}$ gramicidin (Fig. 4A). There was no

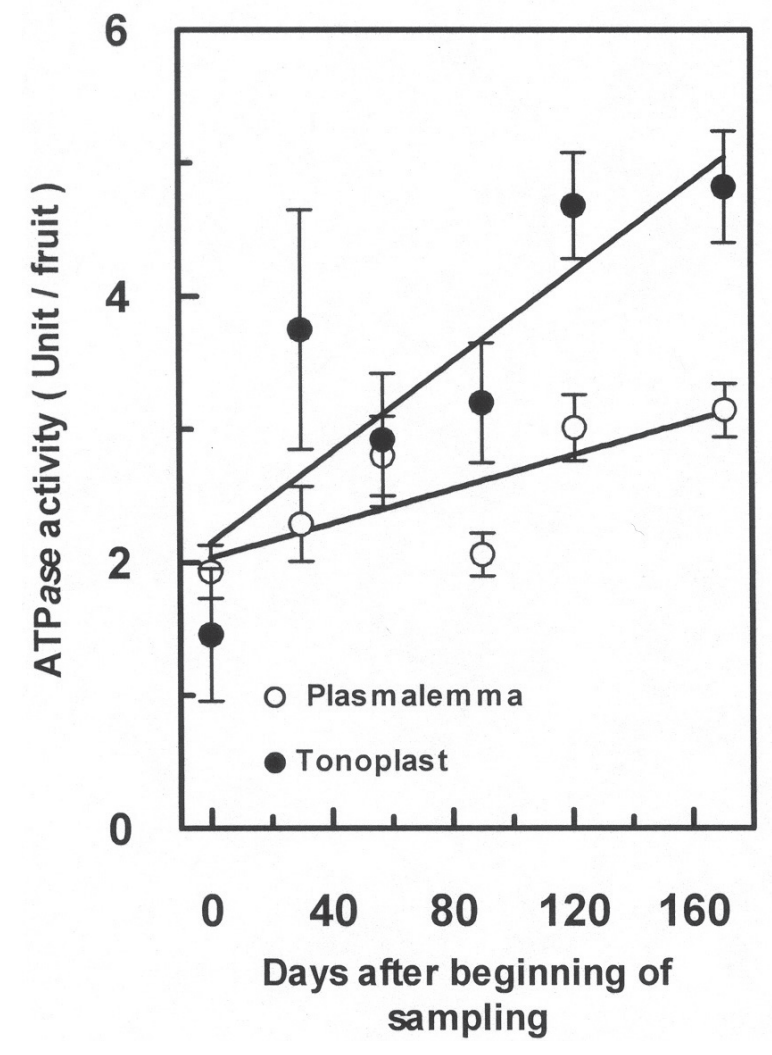

Fig. 2. Activities of V-ATPase and P-ATPase in isolated tonoplast and plasmalemma samples from 'Murcott' mandarin during development. Initial fruit sampling was carried out in 6 Aug. 2002 and terminated in 22 Jan. 2003. One unit is defined as the production of $1 \mu \mathrm{mol}$ of product per minute. Bars indicate standard deviation. 


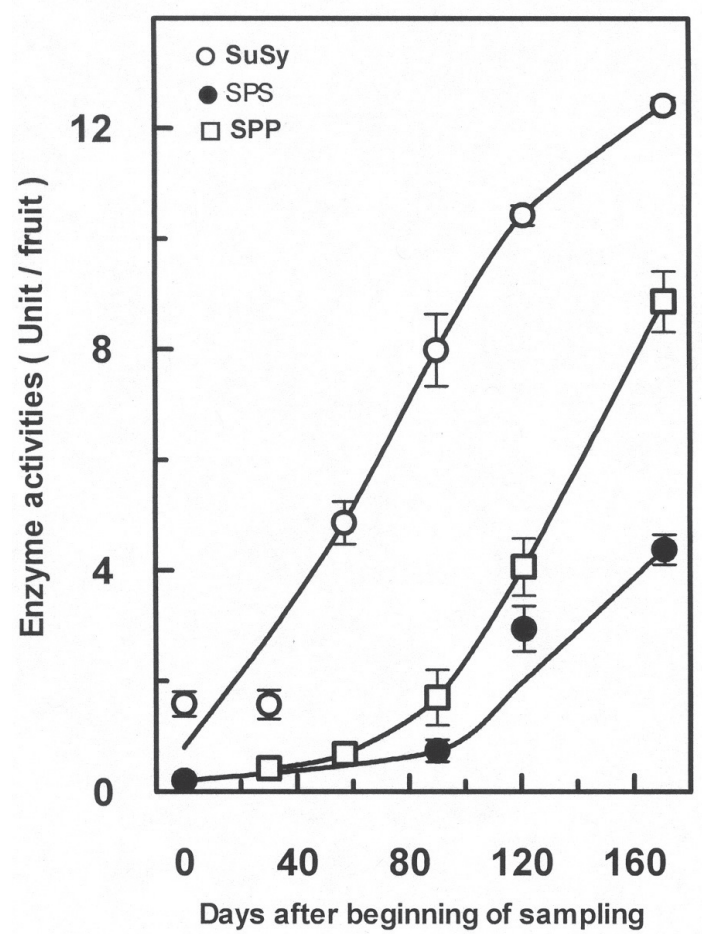

Fig. 3. Activities of enzymes of sucrose metabolism present in citrus juice cells throughout development. Initial fruit sampling was carried out in 6 Aug. 2002 and terminated in $22 \mathrm{Jan}$. 2003. One unit is defined as the production of $1 \mu \mathrm{mol}$ of product per minute. Bars indicate standard deviation.

sucrose uptake in vesicles treated with ATP plus gramicidin (data not shown), eliminating the possibility of a direct ATP-energized sucrose transport system. These results are in accordance with the presence of an electrogenic sucrose carrier at the plasmalemma of citrus juice cells (Garcia-Luis et al., 1991), which mediates transport of sucrose and $\mathrm{H}^{+}$from the apoplast into the cytosol. To our knowledge, this is the first direct demonstration of a sucrose symport at the plasmalemma of storage cells, and further supports the presence of an apoplasmic system of post-phloem transport in citrus fruit (Koch and Avigne, 1990).

In citrus juice cells sucrose is accumulated in the vacuole against a concentration gradient (Echeverria and Valich, 1988), a condition that would require a concurrent active sucrose transport mechanism at the tonoplast. Furthermore, the loss of $\mathrm{H}^{+}$from the vacuole reflected by increase in $\mathrm{pH}$ (Fig. 1B) and the increase in V-ATPase activity (Fig. 2) are properties closely associated with the operation of tonoplast-bound $\mathrm{H}^{+}$antiport systems. When corresponding transport experiments were conducted with tonoplast vesicles, however, no sucrose uptake was measured above control samples (Fig.4B). In fact, addition of ATP alone resulted in lower accumulation of sucrose (Fig. 4B) likely due to the activation of the tonoplast-bound ATP/sucrose export pump (Echeverria and Gonzalez, 2000). The lack of an active sucrose transport system, as that reported for red beet hypocotyl (Getz, 1991) and japanese artichoke tubers (Keller, 1992) was unexpected, given the accumulation of sucrose against a concentration gradient in the vacuole (Echeverria and Valich, 1988) and the presence of sucrose symport activity at the plasmalemma (Fig. 4A). Therefore, the decline in $\mathrm{H}^{+}$concentration in the vacuole is not linked to sucrose $/ \mathrm{H}^{+}$exchange, but to the formation of $\mathrm{PP} i$ by the reverse action of V-PPase as demonstrated for acid limes (Citrus aurantifolia L.) (Marsh et al., 2000).

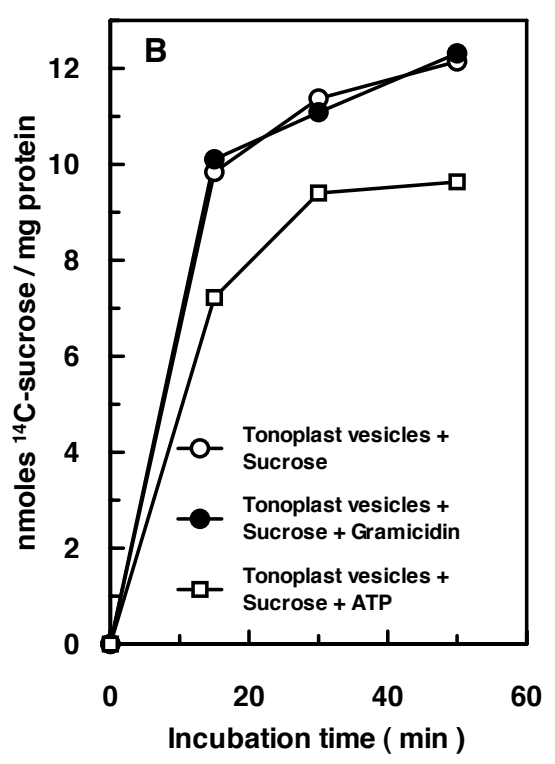

60

Fig. 4. ${ }^{14} \mathrm{C}$-sucrose uptake into purified plasmalemma vesicles (A) and tonoplast vesicles (B) from 'Murcott' mandarin. Vesicles were energized using a pH jump (Bush, 1989) of 2 units and incubated in the presence of $2.5 \mathrm{~mm} \mathrm{Mg} / \mathrm{ATP}$ or $10 \mu \mathrm{M}$ gramicidin (control).

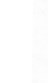

西

$+$

70

20

60

60
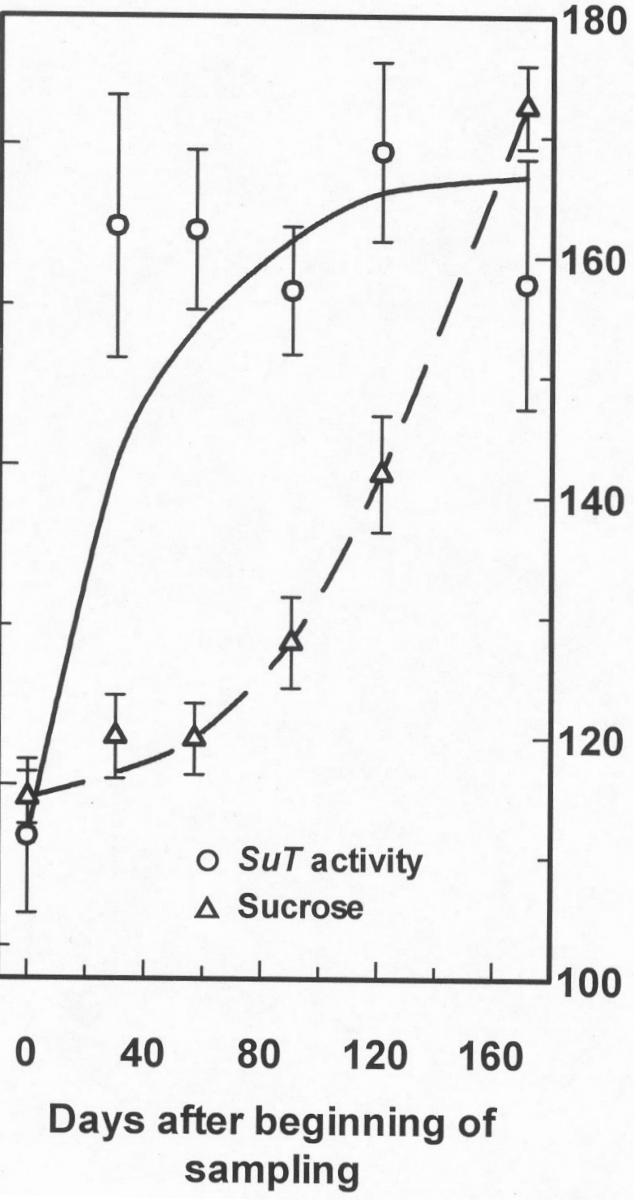

Fig. 5. Plasmalemma sucrose transport activity from 'Murcott' mandarin juice cells throughout development (solid line). Initial fruit sampling was carried out in 6 Aug. 2002 and terminated in 22 Jan. 2003. Dotted line represents the parallel increase in fruit sucrose content. Bars indicate standard deviation. 


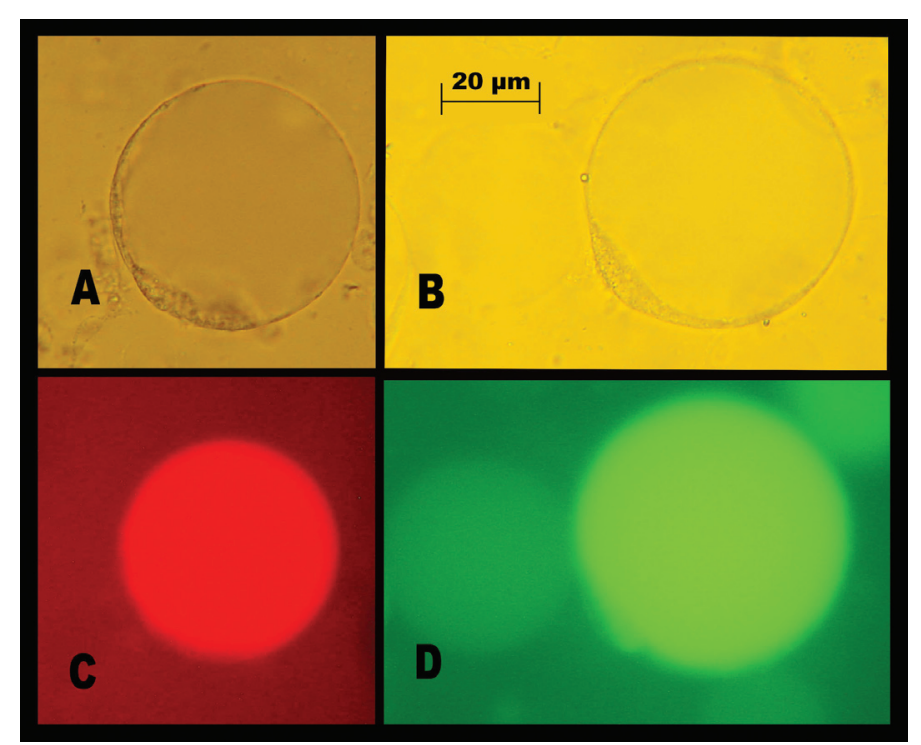

Fig. 6. Light $(\mathbf{A}, \mathbf{B})$ and flourescent micrographs $(\mathbf{C}, \mathbf{D})$ of juice cells after incubation with the membrane-impermeable markers d-TR (C) and in Alexa-488 (D). Protoplasts were prepared for observation after for juice sacs were incubated in $250 \mathrm{~mm}$ sucrose and the respective fluorescent marker for $24 \mathrm{~h}$.

The possibility of a tonoplast-bound active sucrose transport system present only at some critical stages of sucrose accumulation was tested using tonoplast samples collected from fruit at different developmental stages. At no time during fruit development was sucrose uptake into tonoplast vesicles energized by an imposed $\Delta \mu \mathrm{H}^{+}$or ATP alone compared to de-energized vesicles samples. On the contrary, in plasmalemma samples, electrogenic sucrose transport was present at all stages and parallel sucrose accumulation (Fig. 5).

Presence of an active mechanism for sucrose transport only at the plasmalemma does not concur with sucrose being accumulated in the vacuole of juice cells against a concentration gradient. However, this discrepancy would be true only if transport of sucrose occurs sequentially across the plasmalemma, through the cytosol, and finally across the tonoplast prior to eventual accumulation into the vacuole. The possibility of a direct route between the apoplast and the vacuole, as recently inferred by the results of Emans et al. (2002) and Baluška et al. (2004), was investigated by incubating juice sacs (containing juice cells) overnight in a buffered solution of $250 \mathrm{~mm}$ sucrose and the fluorescent membrane-impermeable dyes d-TR (Horn et al., 1992) or Alexa-488 (Emans et al., 2002). After $24 \mathrm{~h}$ of incubation, protoplasts were prepared for better visualization. Microscopic examination of protoplasts revealed a highly fluorescent vacuole indicating transport and accumulation within the vacuolar compartment of both dyes (Fig. 6). The vacuole, which occupies most of the cell volume, is highly fluorescent in both cases, whereas the cytosol is seen as a non-fluorescent layer located at one side of the cell. Given the inability of these compounds to traverse biological membranes, the results of Fig. 6 support the existence of an alternative mechanism of direct solute transport from the apoplast to the vacuole that bypasses transport of across the soluble phase of the cytosol.

Closer examination using high definition confocal microscopy of juice cells incubated for $2 \mathrm{~h}$ in a solution containing Alexa-488, d-TR and sucrose, provided stronger evidence for an endocytic mechanism for sucrose transport into the vacuole of juice cells. In Fig. 7 (arrows), both Alexa-488 and d-TR are internalized into

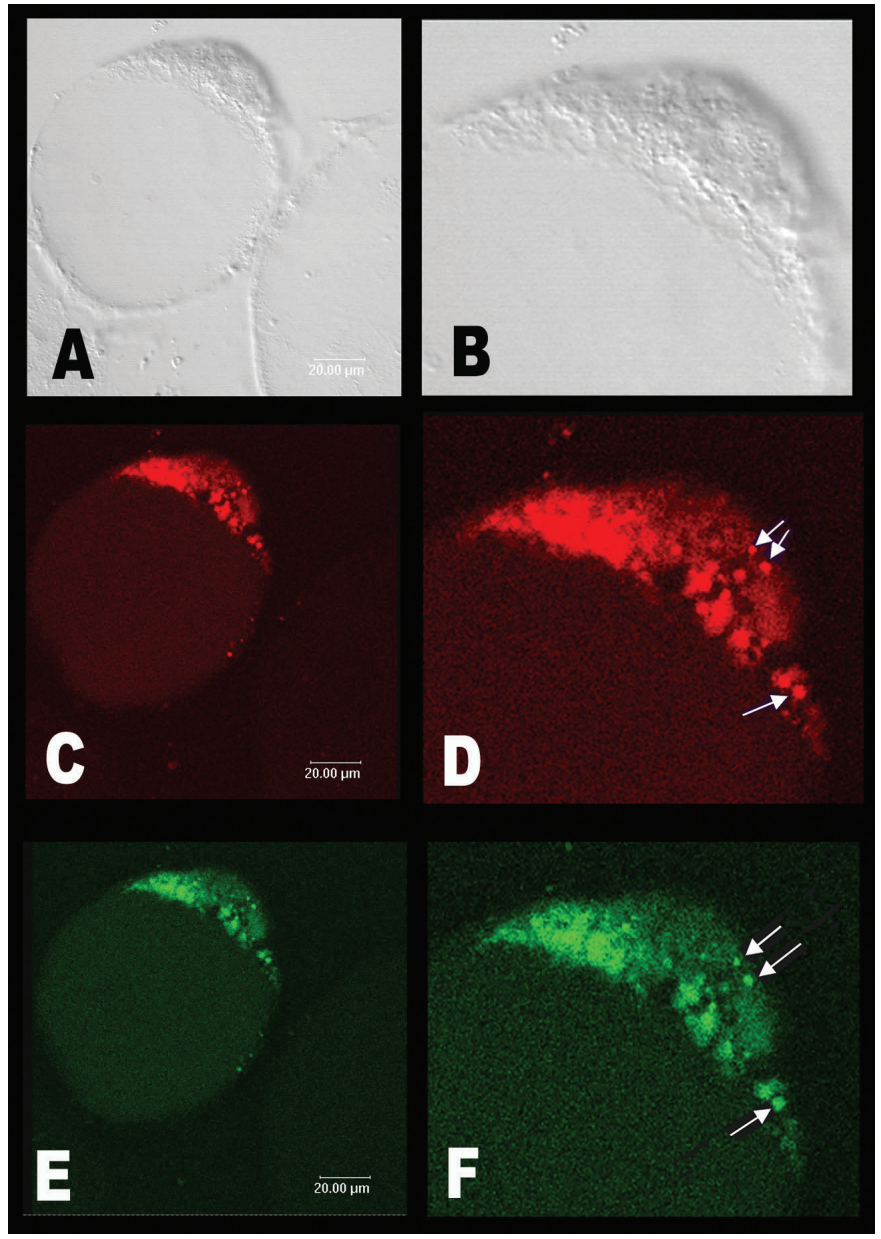

Fig. 7. Light and confocal fluorescent micrographs of a citrus juice cell after 2 $\mathrm{h}$ incubation with sucrose and the membrane impermeable markers d-TR and Alexa-488. A and $\mathbf{B}$ represent light images of the cell in two magnifications. $\mathbf{C}$ and $\mathbf{D}$ correspond to images taken under appropriate filter for d-TR. Images in $\mathbf{E}$ and $\mathbf{F}$ are taken under filter for Alexa-488. Arrows indicate some of many intracellular vesicles containing both d-TR and Alexa-488 simultaneously.

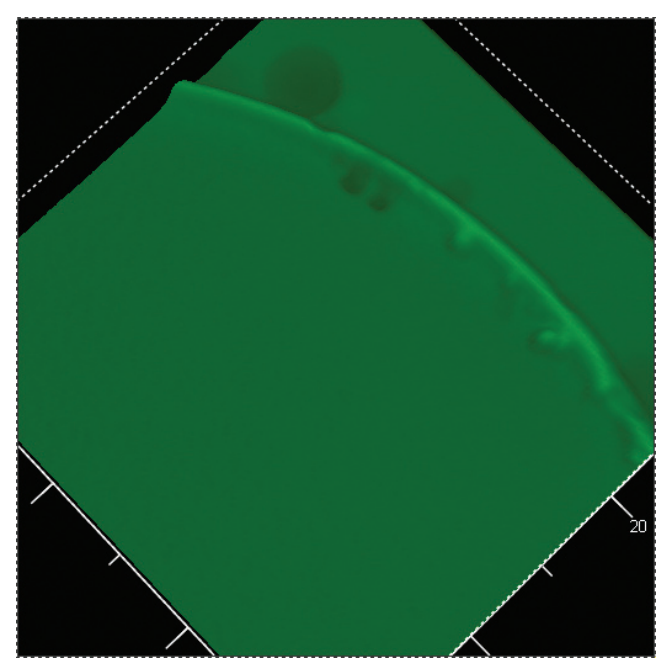

Fig. 8. Topographic high definition confocal fluorescent micrograph of a portion of the plasmalemma from citrus juice cells after 2-h incubation in sucrose and Alexa-488. Note the vesicles budding from the plasmalemma at a time where endocytosis had commenced. 
distinct cytoplasmic compartments within the cytosol. At this time, fluorescence of both dyes appear co-localized within individual compartments whereas no fluorescence was observed in the vacuole. The fact that both dyes appear within the same vesicles reflects the non-selective nature of the uptake process which is highly consistent with properties of an endocytic system. The larger fluorescent areas within the cytoplasm can not be unmistakably identified, however, according to typical endocytic events, these are likely the early endosome and/or the multivesicular body which serve as distribution centers for endocytic contents. Topographic confocal membrane analysis of the plasmalemma of a juice cell during sucrose accumulation (Fig. 8) further substantiates the presence of an endocytic transport mechanism by demonstrating the formation of vesicles of characteristic size of $\approx 70 \mathrm{~nm}$ (Thiel et al., 1998).

Taken together, the data presented in this communication demonstrates for the first time the existence of an active sucrose $/ \mathrm{H}^{+}$ symport at the plasmalemma of storage cells using highly purified right-side out plasmalemma vesicles from citrus juice cells (Fig. 4A). The plasmalemma-bound sucrose symporter mediates the electrogenic transport of sucrose from the apoplast into the cytosol. However, accumulation of sucrose into the vacuole appears not to be carrier mediated given the lack of sucrose transport into energized tonoplast vesicles (Fig. 4B). Instead, the data provide evidence for the existence of a nonselective vesicle mediated mechanism of solute transport consistent with properties of an endocytic system similar to those reported for parenchyma cells of maize root cortex (Baluška et al., 2004) and for tobacco (Nicotiana tabacum L.) cultured cells (Emans et al., 2002). An endocytic system can transport sucrose from the apoplast directly to the vacuole bypassing the cytosol as evidenced by the accumulation of d-TR and Alexa-488 in the vacuole (Fig. 6) and by high resolution confocal microscopy (Figs. 7 and 8).

\section{Literature Cited}

Amor, Y., C.H. Haigler, S. Johnson, M. Wainscott, and D.P. Delmer. 1995. A membrane-associated form of sucrose synthase and its potential role in synthesis of cellulose and callose. Proc. Natl. Acad. Sci. USA 92:9353-9357.

Baluška, F., J. Samaj, A. Hlacvacka, J. Kendrick-Jones, and D. Vilkamann. 2004. Actin-dependent fluid-phase endocytosis oin inner cortex cells of maize root apices. J. Expt. Bot. 55:463-473.

Black, C.C., T. Loboda, J.Q. Chen, and S.J. Sung. 1995. Can sucrose cleavage enzymes serve as markers for sink strength and is sucrose a signal molecule during plant sink development? In Sucrose metabolism, biochemistry, physiology and molecular biology. Current Topics Plant Physiol. 14:49-64.

Bush, D.R. 1989. Proton coupled sucrose transport in plasmalemma vesicles isolated from sugar beet leaves. Plant Physiol. 89:1318-1323.

Chifflett, S., A. Torriglia, A. Chisea, and S. Tolosa. 1988. A method for the determination of inorganic phosphate in the presence of labile organic phosphate and high concentrations of protein: Application to lens ATPase. Anal. Biochem. 168:1-4.

Echeverria, E. and J.K. Burns. 1989. Vacuolar acid hydrolysis as a physiological mechanism for sucrose breakdown. Plant Physiol. 90:530-533.
Echeverria, E., J.K. Burns, and H. Felle. 1992. Compartmentation and cellular conditions controlling sucrose breakdown in mature acid lime fruit. Phytochemistry 31:4091-4095.

Echeveria, E. and P. Gonzalez. 2000. ATP-induced sucrose efflux from red-beet tonoplast vesicles. Planta 211:77-84.

Echeverria, E., P.C. Gonzalez, and A. Brune. 1997. Characterization of proton and sugar transport at the tonoplast of sweet lime (Citrus limmetioides) juice cells. Physiol. Plant. 101:291-300.

Echeverria, E. and J. Valich. 1988. Carbohydrate and enzyme distribution in protoplasts from 'Valencia' orange juice sacs. Phytochemistry 27:73-76

Emans, N., S. Zimmermann, and G. R. Fischer. 2002. Uptake of a fluorescent marker in plant cells is sensitive to brefeldin A and wortmannin. Plant Cell 14:71-86.

Etxeberria, E. and P. Gonzalez. 2003. Simultaneous isolation of tonoplast and plasmalemma from Citrus juice cells by combining density gradient and aqueous two phase partitioning. HortScience 39:174-176.

Garcia-Luis, A., F. Didehvar, J.L. Guardiola, and D.A. Baker. 1991. The transport of sugars in developing fruit of Satsuma mandarin. Ann. Bot. 68:349-357.

Getz, H.P. 1991. Sucrose transport in tonoplast vesicles of red beet roots is linked to ATP hydrolysis. Planta 185:261-268.

Hockema, B.R. and E. Etxeberria. 2001. Metabolic contributors to drought-enhanced accumulation of sugars and acids in oranges. J. Amer. Soc. Hort. Sci. 126:599-2001.

Horn, M.A., P.F. Heinstein, and P.S. Low. 1992. Characterization of parameters influencing receptor-mediated endocytosis in cultured soybean cells. Plant Physiol. 98:673-769.

Keller, F. 1992. Transport of stachyose and sucrose by vacuoles of japanese artichoke (Stachys sieboldii) tubers. Plant Physiol. 98:442-445.

Koch, K.E. 1984. The path of photosynthate translocation into citrus fruit. Plant Cell Environ. 7:647-653.

Koch, K.E. and W.T. Avigne. 1990. Postphloem, non-vascular transfer in citrus: kinetics, metabolism, and sugar gradients. Plant Physiol. 93:1405-1416.

Manning, K., C. Davies, H.C. Bowen, and P.J. White. 2001. Functional characterization of two ripening-related sucrose transporters from grape berries. Ann. Bot. 87:125-129.

Marsh, K., P. Gonzalez, and E. Echeverria. 2000. PPi formation by reversal of the tonoplast-bound $\mathrm{H}^{+}$-pyrophosphatase from Valencia orange juice cells. J. Amer. Soc. Hort. Sci. 125:420-424.

Murata, T. 1977. Studies on the postharvest physiology and storage of citrus fruit. J. Jpn. Soc. Hort. Sci. 46:283-287.

Patrick, J.W. 1997. Phloem unloading: Sieve element unloading and post-sieve element transport. Annu. Rev. Plant Physiol. Mol. Biol. 1997:191-222.

Rosche E., D. Blackmore, M. Tegeder, T. Richardson, H. Schroeder, T.J. Higgins, W.B. Frommer, C.E. Offler, and J.W. Patrick. 2002. Seed-specific overexpression of a potato sucrose transporter increases sucrose uptake and growth rates of developing pea cotyledons. Plant J. 30:165-175

Soule, J. and W. Grierson. 1986. Anatomy and physiology, p. 1-22. In: W. Wardowski, S. Nagy, and W. Grierson (eds.). Fresh citrus fruit. AVI, Westport, Conn.

Thiel, G., M. Kreft, and R. Zorec. 1998. Unitary exocytotic and endocytotic events in Zea mays L. coleoptile protoplasts. Plant J. 13:117-120

Van Handel, E. 1968. Direct microdetermination of sucrose. Anal. Biochem 22:280-283. 